\title{
Estudos migratórios e os desafios da pesquisa de campo
}

\author{
Andréa Vettorassi \\ Professora doutora da Universidade Federal de Goiás, Brasil \\ andreavettorassi@yahoo.com.br \\ Gustavo Dias \\ Professor doutor da Universidade Estadual de Montes Claros, Brasil \\ tentonidias@hotmail.com
}

Resumo O fenômeno migratório tem sido uma preocupação recorrente das pesquisas nas ciências sociais. Todavia, ressaltamos a necessidade de aprofundarmos o debate acerca do método de pesquisa utilizado. Em outras palavras, argumentamos que, tão importante quanto revelar os dados obtidos no trabalho de campo, é a apresentação das ferramentas metodológicas utilizadas, bem como seu poder de apreensão do fenômeno investigado e suas limitações. Neste contexto, e a partir do aumento significativo dos deslocamentos humanos em todas as suas expressões (emigração, imigração, refúgio, retorno, trânsito, tráfico e contrabando de pessoas, etc.), o artigo oferece um breve panorama histórico sobre abordagens teórico-metodológicas utilizadas em estudos sobre mobilidade migratória. Notadamente, refletimos sobre algumas das principais estratégias que se fizeram presentes no campo da antropologia e da sociologia, desde a primeira metade do século XX até a contemporaneidade.

Palavras-chave: Mobilidade migratória, metodologias, estudos migratórios, sociologia, antropologia.

\section{Introdução}

Ao nos ater à produção científica atual no campo dos estudos migratórios que vem sendo desenvolvida no Brasil, o que nos chama a atenção é a falta de uma discussão mais aprofundada sobre as perspectivas metodológicas. Como pesquisadores, sentimos que, por exemplo, a chamada de dossiês, GTs e mesas-redondas em eventos acadêmicos têm trabalhado com recortes amplos em demasiado. Claro, são produções que buscam 
abarcar a complexidade desse campo interdisciplinar. Porém, a riqueza do trabalho fica essencialmente centrada nas revelações de campo oferecidas pelos autores. Sentimos que, para aqueles pesquisadores, sobretudo, em início de estudo, que buscam por respostas para suas dúvidas metodológicas nesses eventos e produções, muitas lacunas ficavam em aberto. Questões como, por exemplo: "Qual o tipo de entrevista mais apropriada para coletar dados? Como acessar determinados grupos envolvidos na mobilidade pesquisada? Onde essa migração, efetivamente, inicia? O local pesquisado é, de fato, o destino? Ou é um local de passagem?”, certamente não são saciadas, já que não constituíam o debate central dessa produção. Deste modo, trazemos para o debate, neste artigo, um dos elementos mais desafiadores para qualquer pesquisador em estudos migratórios quando se lança ao trabalho de campo: o método de pesquisa.

Atuando como uma espécie de texto introdutório ao dossiê apresentado pela revista, demonstramos a relevância do método de pesquisa nos estudos migratórios. Dado que o tema é de extrema vastidão, propomos explorar algumas das principais contribuições metodológicas desenvolvidas nos estudos migratórios. Assim, abrimos o artigo explorando, de forma introdutória, alguns dos principais trabalhos metodológicos sobre migração que surgiram por meio de pesquisadores ligados à Escola de Chicago, durante a primeira metade do século XX, e, no Brasil, por meio da figura de Emilio Willems. Em seguida, o artigo explora as inovações significativas no campo dos estudos migratórios e, sobretudo, na forma de conduzir pesquisas durante a segunda metade do século XX.Aqui, destacamos dois pesquisadores: Abdelmalek Sayad, falecido há 20 anos, em 13 de março de 1998, e George Emmanuel Marcus. Como será apresentado, Sayad, por meio de técnicas de pesquisa bastante simétricas, utilizadas no estudo da migração magrebina para a França, será capaz de oferecer novas perspectivas. Como veremos, em seu estudo, o migrante é o personagem central. Mais do que o pesquisador e suas inquietações, é o entrevistado, por meio de seu próprio idioma, quem revela o fenômeno migratório. Marcus, por sua vez, nos trará contribuições metodológicas por meio de sua etnografia multissituada. Tal proposta lança luz sobre os estudos migratórios, ao nos possibilitar pensar a migração para além dos supostos pontos de chegada ou de saída. A categoria espaço passa a ganhar uma importância de ator social nos estudos migratórios.

Findada essa primeira discussão, na parte seguinte voltamos os olhos para as possibilidades metodológicas em estudos sobre migrações em território brasileiro na segunda metade de século XX e início do século XXI. Métodos como os nós e as redes, amparados por técnicas de pesquisa como a história oral, as fotografias e os mapas afetivos, objetivam abarcar a complexidade não apenas das identidades migratórias e daqueles grupos que, nas cidades receptoras, convivem com os grupos migrantes, mas também a complexidade dos tempos e espaços vivenciados pelos entrevistados. Como será perceptível, esses debates vão ao encontro das inquietações já experimentadas por Sayad e Marcus e corroboram uma perspectiva interdisciplinar e ampliada do fenômeno migratório e dos mais diversos elementos que o compõem. Logo, procuramos trazer, 
ao debate, essas inquietações metodológicas, que são também nossas inquietações na condição de pesquisadores no campo das migrações em suas mais diversas perspectivas.

\section{Os desafios da pesquisa de campo}

Pela complexidade do fenômeno e suas consequências nos aspectos políticos, culturais e econômicos das sociedades contemporâneas, as migrações figuram como uma preocupação recorrente das pesquisas nas ciências sociais. Se, em um primeiro momento, os pensadores europeus clássicos da sociologia conferiram um caráter secundário ao tema, o crescente avanço do campo no último século nos faz perceber um aumento da complexidade no processo e sua relevância para as ciências sociais. Theodoros Iosifides (2011), em seu livro Qualitative methods in migration studies: a critical realist perspective, revela que, durante muito tempo, os estudos migratórios estiveram essencialmente dominados por uma perspectiva empiricista-positivista e associados a pesquisas quantitativas. Todavia, nas últimas décadas, presenciamos um crescente interesse em diversos temas relacionados à migração que, por sua vez, possibilitaram o avanço em pesquisas de cunho qualitativo. Segundo o autor, o avanço em técnicas de entrevistas e observação participante ganharam importância para compreender as complexidades da migração para além da estrutura ou da agência.

Métodos de pesquisa criados e utilizados ao longo desses períodos demonstraram sua validade e são utilizados ainda hoje para registrar e compreender a mobilidade espacial produzida por distintos grupos migratórios. Através de um rápido retrospecto produzido por Franck Düvell (2012), podemos conhecer melhor alguns autores que deixaram sua grande contribuição. Düvell nos revela que, já na primeira metade do século XX, estudos qualitativos desenvolvidos por Florian Znaniecki e William Thomas (1918) e Louis Wirth (1928), por exemplo, através de extenso trabalho de campo, análise de documentos pessoais, observação participante e entrevistas qualitativas, procuraram compreender as condições de vida de migrantes europeus nos Estados Unidos. Ainda atrelada aos estudos produzidos pela Escola de Chicago, durante a primeira metade do século XX, podemos destacar a análise qualitativa produzida por John Lindberg (1930), em The background of Swedish emigration to the United States: an economic and sociological study in the dynamics of migration, para compreender o funcionamento das redes migratórias conectando a Suécia aos Estados Unidos, e o trabalho seminal de William Foote Whyte (1943), denominado Street corner society: the social sructure of an Italian slum. Inicialmente pouco contemplado pela academia, esse estudo dedicado a explorar as condições de vida de migrantes italianos no subúrbio de Chicago se tornaria pioneiro no método da observação participante para os estudos migratórios. Através de uma intensa convivência com jovens migrantes e membros de gangues, Whyte descreveu o funcionamento da estrutura social desse grupo. Interpretado, por essas pesquisas pioneiras, como minorias marcadas por vidas precarizadas, o migrante e sua condição existencial paradoxal começam a ganhar relevância para a sociologia. 
Como Pierre Bourdieu (1998) diz, a sociologia do migrante assume um compromisso com a parte inferior da hierarquia social.

Paralelamente aos estudos desenvolvidos nos Estados Unidos, Emilio Willems, sociólogo e antropólogo de origem alemã e radicado no Brasil, procurou analisar as populações teutobrasileiras localizadas no Espírito Santo e em Santa Catarina. Em seus livros Assimilação e populações marginais no Brasil (1940) e $A$ aculturação dos alemães no Brasil: estudo antropológico dos imigrantes alemães e seus descendentes no Brasil (1980), Willems analisa a migração alemã no Brasil através de noções da então recente antropologia cultural, que surgem como uma outra possibilidade de classificação social do mundo que não a racial (Voigt, 2007).

Assim, através de conceitos como assimilação e aculturação, tão em voga no seu período, esse pesquisador desenvolveu extensos trabalhos de observação da vida dos colonos, conversas com antigos migrantes e anotações de campo, reforçadas com dados históricos, com o intuito de compreender a assimilação do migrante alemão e de seus descendentes na sociedade brasileira (Boas, 2000). Para Willems, um dos fatores mais relevantes na análise da aculturação estaria no idioma alemão e nas suas transformações linguísticas, oriundas do contato entre o idioma do país de origem e o idioma do país adotivo. A língua materna, ou die Muttersprache, havia sido eleita pelos teuto-brasileiros como sendo o principal ponto de referência cultural em torno do qual eles deveriam se organizar, a forma basilar de identificação étnica desse grupo com a nacionalidade alemã ou o Deutschtum (Dias, 2006) ${ }^{1}$.

Será, ainda, durante a segunda metade do século XX que presenciaremos inovações significativas no campo dos estudos migratórios e, sobretudo, na forma de conduzir pesquisas. Dada a amplitude do tema, focaremos neste artigo o uso de entrevistas e da etnografia multissituada como métodos de pesquisa nos estudos migratórios. Elencamos esses dois elementos por terem sido constantemente tema de reflexão para dois autores que deixaram enorme contribuição aos estudos migratórios contemporâneos:Abdelmalek Sayad, de quem se celebra, em 2018, os 20 anos de sua morte, e George Emmanuel Marcus. Nessa perspectiva, faremos o mesmo recorte para apresentar os estudos migratórios contemporâneos no Brasil que, em perspectivas mais qualitativas que quantitativas, buscaram compreender o migrante e sua identidade multifacetada.

$\mathrm{Na}$ segunda metade do século XX, podemos dizer que a preocupação central dos estudos migratórios voltou-se para compreender os motivos que alimentam a circularidade de trabalhadores de países do então Terceiro Mundo, em direção aos países do Primeiro Mundo. Como Iosifides (2011), Stephen Castles e Mark Miller (2009) chamam-nos a atenção, abranger a grande circulação populacional da África, da América Latina e da Ásia em direção às potências europeias e para os Estados Unidos era a questão central das ditas teorias neoclássicas ${ }^{2}$. Num plano macro, esses fluxos migratórios eram interpretados, em

1 Emilio Willems deixou um legado de pesquisa que, certamente, viria a ser retrabalhado e enriquecido posteriormente por Giralda Seyferth, antropóloga e pesquisadora da migração alemã no Sul do Brasil, que faleceu em 6 de abril de 2017.

2 Para aprofundar nesse tema em específico, ver Harris e Todaro (1970), Portes (1983) e Massey et al. (1993). 
geral, como uma busca por um equilíbrio global das economias por meio da repulsão e da atração de trabalhadores; os países periféricos funcionariam como polos de repulsão de trabalhadores, enquanto os países centrais atuariam como áreas de atração deles (Castles; Miller, 2009). No plano micro, Borjas (1990) traz a ideia de um global migration market, no qual os indivíduos são atores racionais que decidem migrar a partir de um cálculo que visa ao máximo retorno financeiro possível. $\mathrm{O}$ cálculo envolveria a probabilidade de encontrar emprego, bem como os custos (materiais, sociais e psicológicos) da viagem, de modo que os indivíduos decidiriam emigrar quando o cálculo resultasse em ganhos financeiros (Fusco, 2002). Abdelmalek Sayad, por sua vez, travará um forte embate teórico e metodológico com tais teorias neoclássicas, fortemente enviesadas pela perspectiva econômica (Martins Jr.; Dias, 2013; Massey et al. 1993; Portes; Böröcz, 1998).

\section{O escrivão público}

Enquanto, no mundo anglo-saxão, os estudos migratórios receberam contribuição fundamental da Escola de Chicago, com técnicas de pesquisas qualitativas inovadoras que exploravam histórias de vida e a investigação etnográfica urbana, o cenário no universo francófono era mais fechado. Sidi Mohammed Mohammedi, no prefácio do livro Abdelmalek Sayad, migrations et mondialisation (2014), observa que, na academia francesa (e aqui ele inclui suas colônias, em especifico a Argélia),

[o] surgimento de um campo de estudo específico sobre o fenômeno migratório foi dificil apesar de ter tido um interesse político e midiático para "o problema da imigração". Diversas perspectivas teóricas foram utilizadas para explicar esse fato: a divisão do trabalho científico (o estudo da imigração era uma tradição estabelecida na demografia e na geografia humana), o legado da escola durkheimiana (que não estava interessada no estudo das migrações, com exceção de Maurice Halbwachs), o peso da análise marxista (que favoreceu, em primeiro lugar, a análise através de classes sociais e "o exército de reserva"), as representações coletivas da sociedade francesa (em particular aqueles relacionados à memória colonial). Mas o fator mais importante é que o estudo da migração seguiu marginal no campo cientifico, porque o seu objeto de estudo, a saber, a pessoa do migrante, era marginal (2014, p. 8, tradução nossa).

Será apenas na figura de Abdelmalek Sayad (1933-1998), em meados dos anos 1970, que a academia francesa passará a trazer contribuições originais para o estudo migratório. A própria associação do migrante como um sujeito marginal no campo científico, como expõe Mohammedi, virá do próprio Sayad que, assim como muitos outros intelectuais argelinos, viveu às margens do cenário acadêmico francês ${ }^{3}$. Esse "etnólogo orgânico da migração argelina", nas palavras de Pierre Bourdieu e Loïc Wacquant (2000), afirma que o migrante chega para a sociologia como um problema social. Assim, para ele, o estudo da migração é por excelência o estudo do pequeno. Pequeno não no sentido de importância,mas 
de uma "sociologia dos objetos situados relativamente na parte inferior da hierarquia social dos objetos de estudo, ou 'pequena' sociologia" (Sayad, 1998, p. 22). Pequeno enquanto marginal. É um sujeito que chega com prazo de validade. Uma identidade temporária que tem uma função social clara para a sociedade receptora: trabalhar, enquanto houver trabalho. Provisoriedade e um passado apagado o inserem num lugar social bastardo, a fronteira entre o ser e o não ser social (Bourdieu, 1998, p.11). E aqui habita um dos paradoxos desse sujeito social.

Portanto, não podemos compreender o migrante e sua mobilidade sem questionar o "estatuto social e científico" dado pelo Estado ou pela academia a esse sujeito.É necessário que o pesquisador, como um artesão intelectual, valendo-se do conceito de Wright Mills (1959), ajuste as suas interrogações, seus conceitos, seus instrumentos de pesquisa e seus preceitos a esse objeto e suas particularidades.

Em seus escritos publicados entre as décadas de 1960 e 1990, Sayad revela o fenômeno migratório para além das perspectivas macro ou micro, bem como de uma interpretação essencialmente voltada para o migrante como um Homo Economicus. Ele propôs superar tais dimensões e pensar o fenômeno migratório em sua totalidade. A economia capitalista e seus efeitos de transferência de um campo para outro, de um país para outro, de um continente para outro, de uma civilização para outra, não devem ser os únicos elementos investigados para compreender as condições geradoras e de perpetuação do fenômeno migratório.

Sayad foi incisivo ao dizer que a migração, em sua plenitude, deve ser compreendida como um "fato social total, única característica, aliás, em que há concordância na comunidade cientifica" (1998, p.15, grifo nosso) ${ }^{4}$. No sentido original de Marcel Mauss (2015), ele afirma que o pesquisador deve investigar a migração através de categorias capazes de dialogar com as diversas áreas de conhecimento pelas quais esse fenômeno circunda. Esse movimento é produzido pelo emigrante, aquele que saiu temporariamente da sociedade de emigração, e pelo imigrante, aquele que, ao chegar na sociedade de imigração, nasce para ela. Aqui encontramos outro paradoxo. Afinal, ambos são a mesma e única pessoa. Não à toa, a migração ganha, para ele, as propícias condições para ser interpretada como um fato social completo. Um fenômeno, em sua totalidade, que não pode ser esgotado em um único campo de estudo. Suas diversas facetas possibilitam o diálogo entre as mais diversas áreas (Geografia, Sociologia, Economia, Linguística, Política, Direito, Antropologia, História, Estatística e assim por diante).

Em relação ao método de pesquisa, o conhecimento íntimo da língua e da tradição berbere possibilitou que Sayad pudesse trazer à luz a compreensão do sentido e dos problemas da migração vividos por seus entrevistados nas aldeias de Cabília ou nos subúrbios de Paris, Nanterre e Lion (Sayad, 1998; 2000; 2008a; 2008b; 2008c). Para ele, estudar migração implica, ao pesquisador, se deparar com a falta de uma história registrada através de documentos oficiais e dados sociais rigorosamente coletados e gravados, bem 
como de dados estatísticos suficientemente longos e cuidadosamente armazenados em arquivos. Assim, o pesquisador precisa buscar caminhos alternativos para superar tal lacuna.

O artesanato intelectual é mais do que a mera técnica de obtenção de dados. Não é uma técnica, é uma troca. Não há como utilizar o artesanato sem dar algo em troca do que se recebe. No artesanato, o observador é observado, o decifrador é decifrado. Sem o que não há interação, Sem interação não há como situar e compreender; situar-se e compreender-se no outro (Martins, 2014, p.34)

A arte de encontrar o narrador e ouvi-lo ganha suma importância. Sayad ressalta a importância de o pesquisador conhecer o limite do seu discurso, o discurso do acadêmico. Este, imbuído de autoridade científica, não pode cair no erro de obscurecer o discurso autêntico do informante, aquele que produz a teoria da migração. $\mathrm{O}$ uso da cultura e da língua original na produção do discurso autêntico é o que revela o inédito, o estranho, o outro. Como Sayad bem ressalta, em "Elghorba: O mecanimo de reprodução da emigração", "é por meio de expressões novas tomadas de empréstimo ao francês e reinterpretadas que o informante melhor consegue dar conta de uma experiência que, mesmo que aparece como nova, continua ligada ao campo da tradição [...]" (1998. p. 43). Primeiro gesto de ruptura com um etnocentrismo intelectual, Sayad devolve, através do uso da entrevista, “aos 'imigrantes', que são também 'emigrantes', suas origens, e todas as particularidades que a elas encontram-se associadas e que explicam muitas das diferenças observadas nos destinos posteriores" (Bourdieu, 1998. p.11). Não à toa, Pierre Bourdieu, no prefácio para a obra $A$ imigração ou os paradoxos da alteridade, publicado em francês originalmente em 1991, dirá que, com Sayad (1998, p. 9-10):

o sociólogo torna-se escrivão público. Ele dá voz àqueles que dela são mais cruelmente despossuídos, auxiliando-os por vezes, tanto com seus silêncios quanto com suas perguntas, a encontrar palavras, a reencontrar, para contar uma experiência que a contraria completamente, os dizeres e os provérbios da sabedoria ancestral, as "palavras da tribo" que descrevem seu exílio, elghorba, como um ocidente, uma queda nas trevas, um desastre obscuro. Isto sem jamais instituir-se como porta-voz, sem jamais se valer da palavra dada, como o fazem tantos os defensores imprudentes das boas causas, para dar lições ou exibir bons sentimentos.

Através de entrevistas conduzidas em espaços sociais escolhidos pelos próprios entrevistados, migrantes, retornados, familiares e funcionários do Estado francês, o método aplicado por Sayad buscava valorizar a trajetória migratória vivenciada pelos próprios migrantes e as impressões daqueles que, de certa forma, estão atrelados a esse movimento. Tal recurso revela o elemento paradoxal já mencionado acima: migrante, sociedades de emigração e imigração não são elementos isolados. Eles compõem o mesmo fato social. "De fato, para mim, como para eles [migrantes], a emigração tinha uma dimensão também de continuidade, não só de ruptura" (Bourdieu, 1996, p.165). 


\section{Pesquisas e pesquisadores em movimento}

Todavia, a ressignificação recente das relações sociais diante da compressão do espaço-tempo (Harvey, 1990; Urry, 2000; 2007) propiciou também o debate sobre a necessidade de rever a própria dinâmica da mobilidade migratória contemporânea para dar conta das múltiplas e heterogêneas interconexões entre o local e o global. Com efeito, as transformações provocadas pela globalização nas sociedades contemporâneas em âmbitos como a cultura, a política, a economia, as tecnologias de transporte e informação aumentaram a mobilidade humana e a interdependência entre os países e tornaram cada vez mais transnacionais tanto as práticas dos sujeitos quanto as das instituições. Não obstante, trabalhos recentes, mais dedicados a explorar a relação entre mobilidade migratória e fronteiras, demonstram que os estudos migratórios ainda seguiam confinados a abordagens metodológicas incompletas, uma vez que não cobriam a mobilidade migratória como um todo (Papadopolous; Stephenson; Tsianos, 2008; Schrooten; Salazar; Dias, 2015;Vila, 2000; Riosmena; Massey, 2000).

Segundo essas análises, o campo multidisciplinar dos estudos transnacionais que surgiram na década de 1990, por exemplo, concentravam-se fortemente no início e nos (supostos) pontos finais da mobilidade, prestando atenção específica ao processo de tomada de decisão antes da partida ou após a chegada aos países de destino (King, 2001; Siqueira, 2009). No entanto, as "dificeis condições vividas ao longo das fronteiras, seja por escolha ou por necessidade" (Hunter; Lepley; Nickels, 2010, p. 223, tradução nossa), tipificam a vida daqueles que as atravessam e não são capturadas em sua totalidade. Como resultado, a noção de migração como processo de movimento de um determinado espaço A para outro espaço B tornou-se inadequada, já que não revela as negociações, os espaços sociais e os sujeitos envolvidos na mobilidade entre esses dois pontos (Levitt; Jaworsky, 2007; Khosravi, 2010; Dias, 2016).

O surgimento da etnografia multissituada, fortemente propagada pelo antropólogo George Emmanuel Marcus, através de seu artigo "Ethnography in/of the World System: the emergence of multi-sited ethnography" (1995), trouxe sérias inovações para o avanço metodológico para superar impasses no campo das migrações. Embora essa abordagem metodológica esteja associada aos estudos de cunho mais antropológicos, tornou-se, em pouco tempo, amplamente utilizada em diferentes campos das ciências sociais (Kirby, 2001). Marcus ressalta como os trabalhos produzidos também por disciplinas como, por exemplo, a sociologia e a geografia geraram significativos avanços nos conceitos de espaço e lugar para a pesquisa etnográfica multissituada. Os estudos migratórios, graças ao seu caráter interdisciplinar, ganharam avanços metodológicos de ordem qualitativa significativos.

Segundo o próprio Marcus, os estudos migratórios como um corpo de trabalho muito mais rico em populações móveis e estabelecidas, situadas através de fronteiras, em exílio e em diásporas, poderiam receber grandes beneficios com uma etnografia que também não ficasse confinada em um determinado local, mas que tivesse a capacidade de se desdobrar juntamente com os sujeitos pesquisados (1995, p.104). Logo, para ele, a 
etnografia multissituada não deveria ser meramente entendida como a reprodução e a multiplicação de lugares a serem pesquisados pelo etnógrafo, em que modos e padrões de pesquisa seriam aplicados em cadeia.

Naturalmente, esta questão estava aberta a óbvias críticas de viabilidade, que eu já previra no ensaio original. O que mais me interessava pessoalmente era como o trabalho em um lugar suscitava rotas frequentemente ocultas para outros, precisamente através do trabalho teórico ou conceitual que o etnógrafo pudesse fazer com assuntos específicos e não outros, ou seja, o informante-chave tornando-se o parceiro epistêmico em relações de cumplicidade - um construto com o qual eu já trabalhara na década de 1990. Esta é também a forma como múltiplas escalas e caminhos de consequências não intencionais foram evocados no magistral trabalho de Anna Tsing, de 2005, Frictions, por exemplo (Marcus, 2015, p. 419)

A etnografia multissituada traz um contributo considerável para descrever as maneiras pelas quais o pesquisador pode obter informações, seguindo pessoas, conexões, associações e relações sociais, porque são substancialmente contínuas, mas espacialmente não contíguas através do espaço. Para os estudos migratórios, a etnografia multissituada converge em duas questões significativamente distintas: a busca por uma escala de análise do fenômeno maior do que uma dimensão local e o estudo das conexões entre os lugares que a mobilidade de sujeitos, informações e bens produz. Paolo Boccagni, sociólogo especializado em migrações transnacionais, adota tal leitura e, ainda, sugere que a unidade de pesquisa em estudos migratórios conduzidos através de uma etnografia multissituada deve ser "menos o próprio migrante e mais os laços sociais interpessoais que estes estabelecem ao longo do percurso e com os lugares deixados" (Boccagni, 2010, p. 4, tradução nossa).

Dentre laços, percursos e lugares, voltamos os olhos para as migrações em território brasileiro, de proporções continentais, na tentativa de trazer luz aos desafios de pensar o migrante em contextos muito específicos que neste país se constroem. Em estudos nacionais contemporâneos, métodos como nós e redes, amparados por técnicas de cunho qualitativo como a história oral, as fotografias e os mapas afetivos, vão ao encontro das inquietações presentes desde Sayad até a etnografia multissituada. Na seção seguinte, apresentaremos alguns desses debates e suas possibilidades de pesquisa.

\section{Novas metodologias e técnicas para pensar as migrações? Possibilidades contemporâneas e pesquisas no Brasil}

No último ano do século XX, Moraes Silva (1999) reforça as novas possibilidades de análise das migrações existentes no Brasil quando, em sua obra Errantes do fim do século, não apenas dá luz aos processos de expropriação, exploração, dominação e exclusão pelos quais os migrantes passam, mas os enxerga em torno do conceito de nó, para pensá-los a partir de três importantes vertentes, a saber, classe, gênero e etnia/raça. 
[...] Não é a expropriação que causa as diferenças. O que ocorre é que as desigualdades sociais, frutos das organizações sociais de gênero e étnico-raciais, vão continuar ocorrendo quando essas relações sociais forem produzidas. Desta sorte, o migrante será percebido, por exemplo, enquanto trabalhador e enquanto "negro", "baiano", "mineirada", enfim, diferente do trabalhador do "lugar". O processo de expropriação que desnuda o trabalhador não é independente do processo de exploração-dominação gerado em seguida. Igualizados do ponto de vista da classe social, diferenciar-se-ão a partir das categorias de gênero e étnico-racial. No que tange às mulheres, a dominação já existia anteriormente, o mesmo ocorrendo em relação aos negros e mestiços quanto à raça-etnia (Moraes Silva, 1999, p. 19).

No prefácio desta obra, escrito por Heleieth Saffioti, socióloga que cunhou a ideia de nó como possibilidade metodológica, destaca-se que tal categoria exige um olhar dialético, que se afaste de um raciocínio linear. Aí está o campo fértil para pensar o migrante a partir de inúmeras perspectivas, como a etnografia multissituada, concomitantemente ao trabalho de Moraes Silva, foi capaz de proporcionar. E com esse objetivo em mente, a história oral é forte aliada, um procedimento metodológico estreitamente vinculado à metodologia qualitativa e que mais se relaciona às renovações epistemológicas que os estudos sobre migrações exigem. Essas renovações sugerem uma ligação mais sólida entre investigação e sociedade, uma maior vinculação entre os investigadores e a realidade a que estão integrados, assim como uma maior conexão entre os planos políticos, sociais, econômicos e culturais, até então divididos e estanques. Isto porque seus objetivos e procedimentos referem-se a um caráter eminentemente interdisciplinar, proporcionando um referencial teórico complexo e multifacetado. São inúmeras as possibilidades proporcionadas pela história oral, dentre elas o dimensionamento de uma temporalidade múltipla e que não é linear. O passado e o presente se relacionam através das experiências sensoriais dos entrevistados e entrevistadores. E, nesse contexto, as técnicas podem ser variadas: relatos orais, histórias de vida e, até mesmo, a análise de fotos.

De acordo com Susan Sontag (2004), filósofa dedicada às reflexões sobre a arte de fotografar, a fotografia é um dos mais misteriosos objetos que compõem o ambiente contemporâneo. Isto porque a foto vai muito além de um pedaço de papel, ou mesmo de uma manifestação puramente artística: a foto é, essencialmente, uma experiência capturada, o objeto de uma consciência. Quem fotografa pode, com o seu ato, apropriarse daquilo que é fotografado, porque a imagem fotografada não parece uma manifestação, uma expressão ou uma interpretação daquilo que se fotografa, mas sim um pedaço sólido do mundo, algo que, com todos os seus traços, linhas e cores, realmente fez ou faz parte de uma realidade concreta. Talvez por isso as imagens fotografadas deixaram muito cedo de ser entendidas como manifestações artísticas para se tornarem, definitivamente, um registro, um testemunho dos fatos, do tempo e do espaço.

Para uma reflexão sobre o papel da fotografia na atualidade, é fundamentalmente importante incluir as categorias tempo e espaço nestas reflexões. A fotografia mantém uma relação intensa com o tempo: ela o testemunha, ao mesmo tempo em que o 
congela. Ela o representa e o denuncia, porque é a mais pura evidência da mortalidade, da vulnerabilidade e da mutabilidade daquilo que é fotografado. Ou seja, ela retrata as duras manifestações do tempo, exercidas sobre todas as coisas e pessoas, mas que ficam ainda mais claras quando essas mesmas coisas e pessoas são fotografadas. Por outro lado, o tempo também sabe exercer sua força sobre a fotografia,já que, à medida que vai passando, muda a condição e a carga emocional existente em uma imagem fotográfica. Desta forma, uma fotografia do século passado traz à tona diferentes sentimentos na contemporaneidade do que aqueles ocasionados quando ela foi revelada.

Com a categoria espaço, a fotografia também estabelece relações profundas. Afinal, o "enquadramento" de uma foto não é arbitrário. Assim como enquadramos as nossas memórias e determinamos aquilo que deve ou não ser lembrado, determinamos também quais espaços devem ser preenchidos pelos ângulos da fotografia, quais deles são dignos de se tornarem registros, quais deles devem ou não ser rememorados. Há ainda uma segunda interessante relação estabelecida entre o espaço e a fotografia: esta dobra as imagens e os espaços do mundo e passa uma ideia de acessibilidade que muitas vezes não condiz com a realidade. "Ao munir este mundo, já abarrotado, de uma duplicata do mundo feita de imagens, a fotografia nos faz sentir que o mundo é mais acessível do que é na realidade" (Sontag, 2004, p. 34).

Em geral, aquilo que é digno de se fotografar é considerado um evento justamente por conta das relações que a fotografia exerce com o espaço e o tempo. No entanto, não é a fotografia em si que identifica e determina o que é ou não um evento, mas sim a ideologia existente nas entrelinhas daquilo que foi "escrito com a luz", na photo - grafia. Sem uma relação com o espaço e com o tempo e, principalmente, sem uma visão política, a foto perde totalmente seu significado. Desta forma, analisar fotos e utilizá-las como procedimento metodológico para pensar fluxos migratórios requer uma preocupação cuidadosa em relacioná-las com o tempo e o espaço em que foram tiradas, como também com o que as caracteriza como um evento, ou seja, quais revelações políticas elas podem nos oferecer.

Qual o significado de um portão fechado? Se for o portão de uma pensão de migrantes, pode significar a pobreza existente entre eles e que fica invisível para os olhares dos grupos nativos que os recebem sem necessariamente os acolherem. Se estiver no centro de alguma metrópole, pode significar uma "cultura do medo" entre o grupo nativo que, constantemente inseguro, se fecha para as consequências de sua própria violência simbólica (Bourdieu, 1989). Milhos plantados em um terreno de poucos metros quadrados não são apenas parte de um “quintal”. Se estão nos fundos de uma pensão de migrantes, podem significar um resgate a antigos valores culturais e sociais, assim como um portaretratos na sala, ou ainda as bandeirinhas representantes de alguma festa típica.

E a foto de uma criança refugiada síria morta sobre a areia de uma praia? Compartilhada sucessivas vezes em mídias impressas e meios eletrônicos, transpõe os limites dos trabalhos acadêmicos, causam comoção global e transmutam os contornos até então presentes na discussão sobre refugiados, exigindo políticas públicas mais eficientes. 
Enfim, as fotografias, quando contextualizadas de forma adequada, levando-se em conta as suas representações políticas e sociais, podem nos revelar fatos e detalhes que vão muito além das palavras escritas. Não obstante, as fotografias, com seus enquadramentos, luzes, cores e elementos contidos, podem revelar muito sobre aquele que está fotografando, quais mensagens e aspectos do mundo real foram por ele escolhidos para o registro visual, o que, afinal, suas fotografias querem revelar. "A sabedoria suprema da imagem fotográfica é dizer: 'Aí está a superfície. Agora, imagine - ou, antes, sinta, intua - o que está além, o que deve ser a realidade, se ela tem este aspecto"” (Sontag, 2004, p. 33).

Fotografias são uma associação a vários aspectos e categorias de nossa sociedade, como a modernidade, o tempo, o espaço, as representações políticas, sociais, culturais. A fotografia está também associada àquele que a constrói. Não obstante, pode estar associada àquele que a observa, e esta é uma de suas capacidades mais importantes: ela retrata a realidade dos outros para, enfim, retratar a nossa própria realidade, que muitas vezes, sem ser passível a uma comparação, permanecia oculta. Assim, trabalhos pioneiros como os de Moraes Silva ampliam as possibilidades de análise das migrações quando utilizam a história oral e as fotografias para, numa perspectiva metodológica micro, tornarem possíveis projeções macro para os migrantes e suas trajetórias.

Nessa mesma perspectiva, a utilização do conceito de redes em processos migratórios amplia a noção de cadeias migratórias. A aplicação do conceito de redes esclarece tanto o desígnio de destinos como a admissão no mercado de trabalho nas sociedades que recebem os fluxos migratórios. Ou seja, repensará estudos da teoria sociológica dos anos 1970 e da sociologia do trabalho no Brasil, que atribuíam à migração, geralmente vista numa perspectiva puramente geográfica e quantitativa, uma noção de "desordem", "ermo", como se populações inteiras pudessem se deslocar sem planejarem suas trajetórias e fossem vítimas de processos impessoais. A noção de redes, bem como abordagens qualitativas, dá voz a esses migrantes e a eles atribui identidades multifacetadas, representadas nas relações de trabalho, mas também nas de lazer e em conjunturas políticas, tornando-os efetivamente sujeitos de sua própria história e representantes de enredos presentes tanto nos locais de destino quanto nos locais de partida. Para essa discussão no Brasil, destacamos os trabalhos de Bianco (1987), Menezes (2002), Fontes (2008) e Truzzi (2008).

Na noção de redes, a cultura migratória assume uma variedade de novas configurações, a saber, formas sincréticas, translocais, multiculturais, neotradicionais, apresentadas também por Sahlins (1997) numa perspectiva antropológica. Essas novas configurações são grandes descobertas etnográficas que o estudo de Sahlins objetiva descrever e ressaltar. Assim, homens e mulheres ouvidos recriam o passado e o estado atual de seus cotidianos de acordo com elementos do tempo presente e das relações que mantêm com os outros. São reflexos de uma memória subterrânea, representante de culturas minoritárias e dominadas e que se opõem a uma memória oficial. São nos espaços e nos lugares por eles rememorados que a tradição se estabelece, pois, embora timidamente e com oscilações e características múltiplas, as redes mantêm os elos dos grupos "de fora". Afinal, nenhuma população se deixa deslocar sem resistência, sem levar consigo parte do que entende 
por seu grupo: as relações existentes entre os espaços e os seres que nele habitam não são transpostas e modificadas facilmente, e isto pode ser perceptível em metodologias qualitativas entre grupos migrantes.

Apresentadas essas ressalvas, façamos uma diferenciação entre os termos coesão, inserção, integração e redes. São necessárias extremas cautela e reflexão sobre a utilização desses conceitos. A ideia de inserção e integração remete muito fortemente às teorias da migração e de espaços urbanos da década de 1970, mencionadas anteriormente. Elas trazem à tona uma teoria que defende a ideia de adaptação, de adequação, como se os migrantes perdessem a cultura de seus locais de origem. Ou seja, nos conceitos inserção e integração há uma concepção de que a migração quebra laços, enquanto, na ideia de redes, a migração recompõe laços. Há, portanto, uma contradição entre as duas vertentes conceituais.

A ideia de coesão, por sua vez, especialmente ao refletirmos sobre sua concepção durkheimiana, vai de encontro às percepções de conflito, bastante perceptíveis em quaisquer análises sobre migrações, bastando observar até mesmo discursos de importantes lideranças políticas, como o atual presidente dos Estados Unidos, Donald Trump, que angariou significativos votos fortalecendo a ideia de conflito e violência entre "nativos" e "de fora". Coesão é também, portanto, um conceito perigoso, já que não se pode excluir o conflito fortemente percebido entre os grupos sociais analisados nos estudos sobre migração. De acordo com Bianco (1987,p.20), muitos antropólogos,influenciados por políticas colonialistas, evitam refletir sobre confrontos sociais e destacam a coesão social em detrimento do conflito e da contradição. Realizam estudos atemporais que não compreendem processos, continuidades e descontinuidades em uma perspectiva histórica. É por isso que a pergunta básica da antropologia aos poucos muda: antes se perguntava como a sociedade se mantém. Hoje se pergunta: como a sociedade se transforma? A primeira indagação é claramente durkheimiana e funcional-estruturalista, que privilegia a análise de modelos e regras sociais. A segunda tem uma orientação processual, baseada na teoria da ação influenciada por Marx e Weber, e objetiva captar a variedade e o fluxo social (Bianco, 1987, p. 20).

Truzzi (2008) explora a utilização do conceito de redes em processos migratórios e demonstra como ele ampliou a noção de cadeias migratórias. "Com base em exemplos de experiências migratórias colhidos na literatura, argumenta-se que a noção de redes é crucial a todos os que almejam entender migrações - históricas ou contemporâneas como um processo social" (2008, p. 199).

Truzzi utiliza como referência um artigo de Charles Tilly, de 1978, que fala sobre a arbitrariedade na definição de emigrante. É necessário destacar a distância e a ruptura para compreender um processo migratório. Ainda de acordo com esse artigo, existem tipos mais comuns de mobilidade, que foram classificadas da seguinte forma:

i. locais: quando o indivíduo se desloca para um lugar que já lhe é familiar;

ii. circular: quando ele se desloca num intervalo de tempo definido, e em seu término retorna à sua origem; 
iii. de carreira: quando o indivíduo se desloca respondendo a oportunidades de ocupação em uma profissão que já exerce;

iv. em cadeia: quando indivíduos se deslocam motivados por arranjos e informações fornecidos por parentes e conterrâneos já instalados no local de destino.

Como se trata de um artificio classificatório, podemos observar que as fronteiras entre cada uma das categorias são ambíguas. "Migrações locais parecem, assim, ter contribuído para a formação de uma cultura migratória que pôde se tornar, após algum tempo, intercontinental" (2008, p. 200, grifos do autor). Truzzi, aliás, em parceria com Demartini, lança em 2005 a compilação de capítulos que pensarão técnicas de pesquisa nos estudos migratórios, e ali estão, dentre outras, discussões sobre o uso de cartas e narrativas biográficas para pensar o migrante (propostas por Seyferth) e de processos criminais como fonte para o estudo de relações interétnicas (propostas por Monsma) ${ }^{5}$.

Já na década de 1960, o termo "cadeias", semelhante ao de redes, foi desenvolvido por pesquisadores australianos e originalmente definido como um movimento possível quando migrantes tomam conhecimento sobre as condições sociais (como exemplo, sobre o mercado de trabalho) de um determinado local a partir da comunicação com outros migrantes (parentes e conterrâneos) que já estão nesse local. Assim, a escolha do destino, seu estabelecimento, onde obter trabalho e se relacionar socialmente eram determinados por essas cadeias.

Rede, por sua vez, é um termo que leva em consideração aspectos mais subjetivos. Redes são laços interpessoais que ligam os migrantes, os não migrantes e os migrantes anteriores tanto nas áreas de destino quanto nas áreas de origem. As redes têm funções sociais, pois mantêm o contato frequente entre os indivíduos e podem controlar seus comportamentos, estimulando ou refreando projetos de migração. De acordo com Menezes (2002), a identidade dos trabalhadores migrantes e a percepção de si mesmos são adquiridas através da formação de redes sociais, muitas vezes adquiridas a partir de laços das comunidades de origem e nos valores dos migrantes. Por isso, Menezes defende que ainda há interação e resistência mesmo em ambientes controlados (2002, p. 147).

Neste sentido, os termos "cadeia" e "redes" são semelhantes, mas o último é um pouco mais abrangente, pois pode determinar, inclusive, o grau de resistência dos grupos migrantes diante de dificuldades nos locais de destino. Como os dois conceitos procuram compreender melhor os processos simbólicos, identitários, sociais e econômicos presentes em quaisquer tipos de migração, ambos são importantes para a compreensão das relações sociais entre os migrantes.

Uma variável-chave para a compreensão dos processos migratórios é o modo como uma informação se dissemina. As redes facilitam o círculo de informações, e essas redes têm grau de abrangência muito variado (podem atingir apenas uma família ou toda uma região). De acordo com Truzzi, o migrante passou a ser visto como mobilizador

5 Para maiores informações, ver: DEMARTINI, Z.; TRUZZI, O. (Org.) Estudos migratórios: perspectivas metodológicas. São Carlos: EDUFSCar, 2005. 
de seu capital social". "Assim, as variáveis relacionais, frequentemente acomodadas em uma história narrativa, deslocam, disputam ou pelo menos completam a explicação dos fenômenos migratórios oferecidas pela abordagem estruturalista" (2008, p. 207-208).

As redes sociais podem ser entendidas como meros instrumentos de pesquisa ou métodos de análise, mas, para Truzzi, elas são muito mais do que isso, pois tentam explicar como são forjadas as relações sociais. Elas são um instrumento valioso para o estudo das ações sociais, pois são capazes de condicionar comportamentos. Nesse sentido, elas se opõem aos pressupostos de uma teoria econômica neoclássica (e seu indivíduo hipossocializado), como também se opõem à teoria sociológica funcionalista (e seu indivíduo hiperssocializado), afinal, a partir das redes, o indivíduo em face de uma realidade normativa, que condiciona comportamentos, tem um pouco mais de autonomia para escolher suas próprias condutas e interpretações. É por isso que as redes sociais explicam fluxos migratórios que se estendem mesmo quando as condições sociais que lhe deram início cessam. "Nessa perspectiva, são, portanto, as redes de relações sociais que estruturam oportunidades tanto de partir como de se colocar no novo pás" (2008, p. 210). Truzzi cita Sayad e demonstra que, mesmo sem utilizar o termo "redes", em seus ensaios encontram-se argumentos e análises que consideram as relações sociais dos migrantes, tal qual os estudos sobre as redes.

É também necessário analisar o papel estratégico das redes nas sociedades receptoras, afinal, essa recepção influi na constituição das redes, especialmente quando refletimos sobre aglomerações espaciais e esferas de sociabilidade:

$\mathrm{Na}$ verdade, não são apenas as redes de relações tecidas anteriormente à emigração que desenharão os vínculos étnicos na sociedade receptora: a própria experiência migratória por si só é capaz de propor e redefinir novas identidades e reconhecimentos que podem se traduzir em novas redes. [...] Tilly (1990), por exemplo, refletindo sobre esta questão, proporá que as redes de envio e de recepção de migrantes interagem e conformam novas redes, formadoras de novas sociabilidades (Truzzi, 2008, p. 211).

Em contribuição à reflexão sobre redes sociais, bem como sobre outros conceitos utilizados pela antropologia contemporânea, Bianco (1987) menciona que os antropólogos sempre se basearam em documentação histórica para a reconstrução das sociedades que estudaram, mas esses dados normalmente eram utilizados como "pano de fundo" ao presente etnográfico. Eles devem ser tratados como parte integral da análise antropológica. É necessário aliar dados históricos e processos sociais com interstícios sociais. Esse tipo de investigação possibilita dissolver limites artificialmente criados por antigos pressupostos teóricos e metodológicos.

É possível realizar interpretações amplas a partir de extensivo conhecimento daqueles assuntos extremamente pequenos. É importante resgatar o caráter microscópico da antropologia e a sua particularidade típica em estudar os interstícios sociais, a partir de 
um enfoque que integra a história e os dados documentais à interpretação de processos sociais (Bianco, 1987, p. 36). Neste sentido, o conceito de redes pode ser útil:

Os conceitos de rede social, de quase grupo, a ênfase na fluidez dos agrupamentos sociais e o método de análise situacional constituem esforços neste sentido, mesmo que tenham sido formulados a partir da demarcação artificial do campo de estudos da antropologia (Bianco, 1987, p. 37).

Para uma sociologia desenvolvida na primeira metade do século XX, a migração nordestina para São Paulo era feita por indivíduos que muito demoradamente se acostumavam com condições de vida tão diversas daquelas que tinham em seus locais de origem. Essa falta de identificação e articulação, assim como a persistência de formas de condutas tradicionais, tornaria ausentes possíveis ações coletivas e solidariedades de classe. Fontes (2008) refuta essa análise, já que prova que as redes existentes entre os migrantes em diversas instâncias da vida em sociedade são capazes de lhes atribuírem uma identidade própria diretamente ligada ao trabalho operário. Ou seja, aí está mais um aspecto fundamental para se pensar a identidade migrante: sua relação com o trabalho, demonstrando mais uma vez que são inúmeras as sobreposições presentes nos grupos migratórios e em suas vertentes.

Nessa perspectiva, em que a própria etnografia multissituada, as redes, os nós e outras metodologias inovadoras podem ser capazes de captar as relações multifacetadas que os migrantes e os grupos que os recebem estabelecem com os tempos e espaços diversos que experimentam, voltamos nossos olhos para um novo método de pesquisa que objetiva avaliar as identidades temporais e espaciais dos agentes que experimentam os fluxos migratórios. Esse método foi denominado "mapas afetivos", recurso que objetiva demonstrar como se revelam as lembranças e de que forma elas são transportadas para o papel em desenhos e em falas a partir da história oral (Vettorassi, 2014). Sua aplicação demonstrou que há uma ligação muito estreita entre memória e sentimento de identidade, no sentido de imagem de si, para si e para os outros. Já que a memória e a identidade são avaliadas pelo outro, estas podem ser disputadas em conflitos sociais, políticos, culturais e intergrupais propiciados nas relações de trabalho e nos espaços e tempos do cotidiano dos entrevistados, e esses marcadores sociais podem aparecer de maneiras muito subjetivas e complexas quando outros recursos, como os desenhos, são experimentados ao longo do trabalho etnográfico e na aplicação de entrevistas. Os mapas afetivos são importantes para que, em outras etapas, o trabalho de campo amadureça as constatações que faz diante de elementos objetivos e subjetivos, como os dados demográficos e históricos, as entrevistas, as fotos e as observações proporcionadas pela etnografia.

Sob a perspectiva dos arquétipos, realidade é qualquer elemento que funciona para a vida psíquica. Assim, imaginação é também realidade. A imagem é um conceito ligado ao arquétipo, e imaginar não é igual a devaneio, a "sonhar acordado”. Imaginar é aceitar a visitação da imagem de acordo com aqueles elementos incorporados de sua sociedade, de seus grupos, da sequência de imagens que, em retrospectiva, podem ser a 'imagem 
arquetípica' de situações novas, ou velhas situações com novos valores. "O subjetivo também é real e, para além do subjetivo, o símbolo é real. Mesmo que só possa ser percebido por suas manifestações imagéticas" (Menezes, 2007, p. 110).

Os mapas afetivos demonstraram ser, portanto, uma importante ferramenta metodológica capaz de captar as subjetivas dimensões espaciais e temporais dos entrevistados. Com os mapas afetivos, é possível identificar como os próprios entrevistados veem a si mesmos e aos outros em face de muitas e negociadas identidades. Segundo os mapas afetivos, ou seja, do ponto de vista daqueles que os desenharam, as redes entre os migrantes mais integram que exploram e, geralmente, essas mesmas redes interferem no projeto de "voltar", que é mais presente que o projeto de "ficar". Além disso, os "nativos", ou seja, os moradores das cidades receptoras de migrantes, também têm suas redes e suas visões particulares sobre os espaços e tempos de suas cidades. Os espaços e redes apresentados constituem o que é "seu por direito", ou seja, revelam identidades marcadas pela disputa e pelas transformações sofridas nas configurações de suas cidades.

\section{À guisa de conclusão}

Das vilas, termo para designar as casas que ficavam fora do núcleo central da Roma Antiga e eram habitadas por homens e mulheres do campo, surgiram as palavras vilão e vilania. Estrangeiro e estranho, em sua etimologia, têm a mesma raiz. Não só nas entrelinhas da história observamos contínuas discriminações diante do diferente, mas nas significações nuas e cruas de nossas palavras, de nossos gestos, de nossas reivindicações.

As elucubrações acima registram a importância de se pensar o migrante também como categoria êmica, ou seja, que coloca à tona representações e características dos grupos que os recebem e, por que não, dos grupos que os analisam, que os estudam, que os observam. Destacamos, portanto, aqueles estudos e análises que olharam o fenômeno migratório em suas múltiplas variáveis e categorias e que, numa perspectiva metodológica micro, lançam elementos múltiplos para se pensar as migrações em sua perspectiva macro.

No que tange aos estudos brasileiros, embora haja um número cada vez maior de estudos e cientistas sociais especializados em migrações, há que se ressaltar o intenso crescimento nas últimas décadas dos fluxos migratórios em diversas regiões do país, e não mais nos tradicionais eixos Nordeste/Sudeste, além do caráter transnacional desses fluxos, marcando o Brasil como um país também receptor de emigrantes, em especial de haitianos e sul-americanos. Essa mudança no quadro de migrantes no país interfere, inclusive, nas discussões teóricas e análises empíricas de outras áreas das ciências sociais, como aquelas que estudam as relações de trabalho (em que muitas vezes há trabalhadores migrantes envolvidos nas denúncias de trabalhos análogos à escravidão, por exemplo), a violência (quando o estigmatizado imaginário social e até mesmo instâncias do judiciário correlacionam a migração com o aumento dos índices de criminalidade) e os direitos humanos (tema sempre fundamental e transversal na discussão do cidadão migrante, seus 
direitos e deveres). Além disso, políticas públicas e discussões sobre migrações, cada vez mais presentes nos debates e nas agendas políticas do Brasil e do mundo, dão relevância global e urgência às análises científicas e acadêmicas sobre o tema.

Por isso, é desafio da área reunir esforços para que todos esses elementos estejam presentes no cenário das discussões sobre o migrante e suas vertentes, tornando-o efetivamente um fato social total, como pensou Sayad (1998), e menos uma sociologia do pequeno, já que tem tanto a acrescentar em múltiplas análises sociais e em eixos metodológicos diversos.

\section{Referências}

ARAÚJO, Sandra Gil. Una sociología (de las migraciones) para la resistência. EMPIRIA: Revista de Metodología de Ciencias Sociales, v.19, p. 235-249, 2010.

BIANCO, B. F. (Org.) A antropologia das sociedades contemporâneas. São Paulo: Editora Global. 1987.

BOAS, Glaucia Villas. De Berlim a Brusque, de São Paulo a Nashville: a sociologia de Emílio Willems entre fronteiras. Tempo Social, v.12, n.2., p.171-188, 2000.

BOCCAGNI, Paolo. Exploring migrants' affective ties at a distance: is 'multi-sited' ethnography enough?. COMCAD Arbeitspapiere - Working Papers, v.72, p.2-17, 2010.

BOURDIEU, Pierre. O poder simbólico. Lisboa: Difel, 1989.

Razões práticas: sobre a teoria da ação. Campinas: Editora Papirus, 1996.

Um analista do inconsciente. In: SAYAD, Abdelmalek. A imigração ou os paradoxos da alteridade. São Paulo: EDUSP, 1998.

BOURDIEU, Pierre ; WACQUAINT, Loïc. The organic ethnologist of Algerian migration. Ethnography. v. 1, n. 2.p. 173-182, 2000.

BORJAS, George. Friends or strangers: the impact of immigrants on the U. S. economy.New York: Basic Books, 1990.

CASTLES, Stephen; MILLER, Mark. The age of migration: international population movements in the modern world. New York: Palgrave MacMillan, 2009.

DE GENOVA, Nicholas. Migrant 'illegality' and deportability in everyday life. Annual Review of Anthropology, v. 31, p.419-447, 2002

.The legal production of Mexican/migrant 'illegality'. Latino Studies, v.2, p.160-185, 2004.

.Spectacles of migrant 'illegality': the scene of exclusion, the obscene of inclusion. Ethnic and Racial Studies, v. 36, n. 7, p.1180-1198, 2013.

DEMARTINI, Z.; TRUZZI, O. (Org.) Estudos migratórios: perspectivas metodológicas. São Carlos: EDUFSCar, 2005

DIAS, Gustavo. Cultura, política e alfabetização no Brasil: a "Segunda Campanha de Nacionalização" do ensino (1938-1945). São Carlos. Dissertação (Mestrado em Ciências Sociais) - Universidade Federal de São Carlos, 2006.

Brazilian migration into London: mobility and contemporary borders. 2016.Tese (Doutorado em Sociologia)

- Goldsmiths College/University of London, Goldsmiths, 2016.

. Tactics of border crossing movement: exploring the mobility of Brazilians through the Schengen and UK airspace. Revista Ambivalências, v. 3, n. 5, p.183-215, 2015. 
.Dealing with the UK inner borders: a study of Brazilians and their temporary dwellings in London. Revista Mediações, v. 22, n.1, p.156-182, 2017.

DÜVELL, Franck. Qualitative research in migration studies. Fiesole, Italy: European University Institute, 2012.

FONTES, Paulo. Um Nordeste em São Paulo: trabalhadores migrantes em São Miguel Paulista (1945-1966). Rio de Janeiro: Editora Fundação Getúlio Vargas. 2008.

FUNDAÇÃO CALOUSTE GULBENKIAN. Para abrir as ciências sociais. São Paulo: Cortez Editora, 1996.

FUSCO, Wilson. Redes sociais na migração internacional: o caso de governadorValadares. Textos Nepo, Campinas, v. 40, p. 1-96, 2002.

GULLIVER, Phillip. The family heards. Oxon: Routledge, 2000.

HARRIS, John;TODARO, Michael.Migration, unemployment and development: a two sector analysis. American Migration Review, v.60, n.1, p.126-142, 1970.

HARVEY, David. The condition of postmodernity: an enquiry into the origins of cultural change. Cambridge: Blackwell, 1990.

HUNTER, Cynthia; LEPLEY, Susannah; NICKELS, Samuel. New practice frontiers: Current and future social work with transmigrants. In: NEGI, Nalini; FURMAN, Rich (Eds.). Transnational social work practice. New York: Columbia University Press, 2010.

IOSIFIDES, Theodoros. Qualitative methods in migration studies: a critical realist perspective. Oxford: Ashgate Publishing, 2011.

KHOSRAVI, Sharahm. The 'illegal' traveller: an auto-ethnography of borders. London: Palgrave Macmillan, 2010.

KING, Russel (Org.). The Mediterranean passage: migration and new cultural encounters in Southern Europe. Liverpool: Liverpool University Press, 2001.

KIRBY, Peter Wynn (Org.). Boundless worlds: an anthropological approach to movement. New York: Berghahn Books, 2001.

KRITZ, Mary (Org.), Global trends in migration: theory and research on international population movements. New York: Center for Migration Studies, 1981.

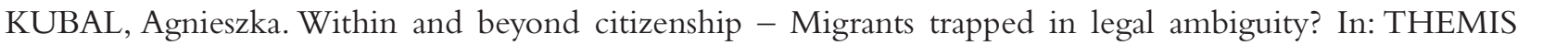
INTERNATIONAL MIGRATION CONFERENCE. April, 2013. Oxford University, 2013.

.Struggles against subjection: implications of criminalization of migration for migrants' everyday lives in Europe. Crime, Law and Social Change, v. 62, n.2, p.91-111, 2014.

LEVITT, Peggy; JAWORSKY, Bernadette. Transnational migration studies: past developments and future trends. Annual Review of Sociology, v.33, n. 1, p.129-156, 2007.

LINDBERG, John. The background of Swedish emigration to the United States: an economic and sociological study in the dynamics of migration. Minnesota: Minnesota Press, 1930.

MARCUS, George Emmanuel. Ethnography in/of the world system: the emergence of multisited ethnography. Annual Review of Anthropology, v.24, p. 95-117, 1995.

Entrevista com George Marcus. Mana, v.21, n.2, p.407- 423, 2015.

MARTINS JR, Angelo; DIAS, Gustavo. Imigração brasileira contemporânea: discursos e práticas de imigrantes brasileiros em Londres. Análise Social, v. 209, n.33, p. 810-832, 2013.

MARTINS, José de Souza. Uma sociologia da vida cotidiana: ensaios na perspectiva de Florestan Fernandes, de Wright Mills e de Henri Lefebvre. São Paulo: Contexto, 2014.

MASSEY, Douglas. Migration, ethnic mobilization and globalization - causes of migration. In: GUIBERNAU, Montserrat; REX, John (Org.). The ethnicity reader - nationalism, multiculturalism and migration. UK: Polity Press, 1997. 
.; ARANGO, Joaquin; HUGO, Grame; KOUAOUCI, Ali; PELLEGRINO, Adele; TAYLOR, Edward. Theories of international migration: a review and appraisal. Population and Development Review, v. 19, n.3, p.431466, 1993.

MAUSS, Marcel. Sociologia e antropologia. São Paulo: Cosac e Naify, 2015.

MENEZES, Francisco Lucena de. Migração: uma perspectiva psicológica, uma leitura pós-moderna ou, simplesmente, uma visão preconceituosa. In: CUNHA et al. (Orgs). Migração e identidade. São Paulo: Editora Centauro, 2007. p. 105-132.

MENEZES, Marilda Aparecida de. Redes e enredos na trilha dos migrantes: um estudo de famílias de camponeses migrantes. Rio de Janeiro: Relume Dumará; João Pessoa: EDUFPB, 2002.

MILLS, Wright. The sociological imagination. New York: Oxford University Press, 1959.

MOHAMMEDI, Sidi Mohammed (Org.). Abdelmalek Sayad, migrations et mondialisation. Oran: Éditions Crasc, 2014.

MORAES SILVA, Maria Aparecida. Errantes do fim do século. São Paulo: Editora UNESP, 1999.

PAPADOPOULOS, Dimitris; STEPHENSON, Niamh;TSIANOS, Vassilis. Escape routes: control and subversion in the 21st century. London: Pluto Press, 2008.

PERERA, Suvendrini. Australia and the insular imagination: beaches, borders, boats, and bodies. New York: Palgrave Macmillan, 2009.

PORTES, Alejandro; BÖRÖCZ. Migración contemporánea. Perspectivas teóricas sobre sus modalidades de incorporación. In:MALGESINI, Graciela (Org.) Cruzando fronteras. Migraciones em el sistema mundial. Barcelona: Fundación Hogar Del Empleado, 1998.

Modes of structural incorporation and present theories of labor immigration. In: KRITZ, Mary; KEELY, Charles; TOMASI, Silvano (Org.). Global trends in migration : theory and research on international population movements. Staten Island, N.Y. : Center for Migration Studies. 1983

RIOSMENA, Fernando; MASSEY, Douglas. Pathways to El Norte: origins, destinations, and characteristics of Mexican migrants to the United States. International Migration Review, v. 46, n.1, p. 3-36, 2000.

SAADA, Emmanuelle. Abdelmalek Sayad and the double absence. French Politics, Culture E Society, v.18, n.1, p. $28-47,2000$.

SAHLINS, Marshall. O pessimismo sentimental e a experiência etnográfica: por que a cultura não é um objeto em via de extinção (parte I). Revista Mana, v. 3, n. 41, p. 45-73, 1997.

SAYAD, Abdelmalek. A imigração ou os paradoxos da alteridade. São Paulo: EDUSP, 1998.

O retorno: elemento constitutivo da condição do imigrante. Travessia especial. revista do migrante, n. 13 , 2000.

A maldição. In: BOURDIEU, Pierre. (Org.). A miséria do mundo. Petrópolis:Vozes, 2008 a.

A emancipação. In: BOURDIEU, Pierre. (Org.). A miséria do mundo. Petrópolis:Vozes, $2008 \mathrm{~b}$.

Uma família deslocada. In: BOURDIEU, Pierre. (Org.). A miséria do mundo. Petrópolis:Vozes, 2008c.

SCHROOTEN, Mieke; SALAZAR, Noel; DIAS, Gustavo. Living in mobility: trajectories of Brazilians in Belgium and the UK. Journal of Ethnic and Migration Studies, London, n. 42, v. 7, p.1199-1215, 2015.

SIQUEIRA, Sueli. Sonhos, sucesso e frustrações na emigração de retorno: Brasil-Estados Unidos. Belo Horizonte: Argvmentvm, 2009.

SONTAG, Susan. Sobre a fotografia. São Paulo: Companhia das Letras. 2004.

TRUZZI, Oswaldo. Redes em processos migratórios. Tempo Social - Revista de Sociologia da USP, São Paulo, v. 20, n. 1. p. 199-218, jun. 2008.

URRY, John. Sociology beyond societies: mobilities for the twenty-first century. London: Routledge, 2000. 
. Mobilities. Cambridge: Polity Press, 2007.

VETTORASSI, Andréa. Mapas afetivos: recursos metodológicos baseados na história oral e reflexões sobre identidades espaciais e temporais em estudo sociológico. História e Cultura, Franca, v.3, n.3 (Especial), p. 155-176, dez. 2014.

VILA, Pablo. Crossing borders, reinforcing borders: social categories, metaphors, and narratives identities on the U.S.Mexico frontier.Austin: University of Texas Press, 2000.

VOIGT, André Fabiano. Emílio Willems e a invenção do teuto-brasileiro, entre a aculturação e a assimilação (1940-1946). História: Questões \& Debates, n. 46, v.1 p. 189-201, 2007.

WHYTE, William Foote. Street corner society: the social structure of an Italian slum. Chicago: University of Chicago Press, 1943.

WILLEMS, Emilio. Assimilação e populações marginais no Brasil. São Paulo: Nacional, 1940.

A aculturação dos alemães no Brasil: estudo antropológico dos imigrantes alemães e seus descendentes no Brasil. 2. ed. São Paulo: Nacional, 1980.

YACINE, Tassadit. Abdelmalek Sayad ou la formation d'un habitus cultivé (1933-1998). In: MOHAMMEDI, Sidi Mohammed (Org.). Abdelmalek Sayad, migrations et mondialisation. Oran: Éditions Crasc, 2014. 


\title{
Migration studies and the challenges for field research
}

\begin{abstract}
Migration has been a recurring issue in research on the Brazilian social sciences. However, we have seen a large number of studies which focus exclusively on revealing the empirical data. Taking this into account, this paper highlights the need of broadening the debate on research methods in migration studies. It argues that addressing the methodological tools - its power of apprehension, interpretation and limitations to explain - designed to explore a particular migration phenomenon must be a recurrent practice among researchers in Brazilian migration studies. So, it presents an introductory historical overview of methodological approaches used in studies on migration mobility. We, particularly, reflect on some of the main strategies developed in the field of anthropology and sociology, from the first half of the twentieth century to the present day, and how it enlarge the debate on research methods in migration studies.
\end{abstract}

Keywords: Migration, methods, migration studies, sociology, anthropology .

\section{Estudios migratorios y los desafíos de la investigación de campo}

\section{Resumen}

El fenómeno migratorio ha sido una preocupación recurrente de las investigaciones en las ciencias sociales. Sin embargo, resaltamos la necesidad de profundizar el debate sobre el método de investigación utilizado. En otras palabras, argumentamos que, tan importante como revelar los datos obtenidos en el trabajo de campo, es la presentación de las herramientas metodológicas utilizadas, así como su poder de aprehensión del fenómeno investigado y sus limitaciones. En este contexto, y a partir del aumento significativo de los desplazamientos humanos en todas sus expresiones (emigración,inmigración, refugio, retorno, tránsito, tráfico y contrabando de personas, etc.), el artículo ofrece un breve panorama histórico sobre enfoques teórico-metodológicos utilizados en estudios sobre movilidad migratoria. En particular, reflexionamos sobre algunas de las principales estrategias que se hicieron presentes en el campo de la antropología y de la sociología, desde la primera mitad del siglo XX hasta la contemporaneidad.

Palabras clave: Movilidad migratoria, metodologías, estudios migratorios, sociología, antropología. 